\title{
Robótica Educacional em escolas públicas
}

\author{
Laureane Pereira de Sousa, Veruska Ribeiro Machado
}

\author{
Campus Taguatinga - Instituto Federal de Brasília (IFB) \\ Brasília - DF - Brazil \\ \{pslaureane@gmail.com, veruska.machado@ifb.edu.br\}
}

\begin{abstract}
Considering the search for methodologies that could alleviate the learning deficit, educational robotics was used as a pedagogical strategy. The goal was to evaluate educational robotics as a strategy to motivate learning and develop in children the basic fundamentals of computing; the ability to apply concepts of mathematics, as well as the ability to solve problems, to work in teams and to communicate. They were used as instruments of data collection: observations in loco; fact sheets and questionnaires. The initiative was developed in 2 phases, through an Introduction to Robotics course, guided by the concept of hybrid teaching, in which topics related to technological culture and computational thinking were worked on. As a result, greater concentration was observed when carrying out the activities; that they can grasp the concepts of computational thinking, programming, and robotics; that the perception of error is seen differently when attempting to construct something; evolution of autonomy and improvement of soft skills.
\end{abstract}

Resumo. Pensando na busca de metodologias que pudessem contribuir para o processo de aprendizagem, utilizou-se a robótica educacional como estratégia pedagógica. O objetivo é avaliar a robótica educacional como estratégia para motivar o aprendizado e desenvolver em crianças os fundamentos básicos da computação; a capacidade de aplicar conceitos da matemática, bem como a capacidade de resolver problemas, de trabalhar em equipe e de se comunicar. Usou-se como instrumentos de coleta de dados: observações in loco; fichas de acompanhamento e questionários. A iniciativa foi desenvolvida em 2 fases, por meio de um curso de Introdução à robótica, orientado pelo conceito de ensino híbrido, no qual foram trabalhados temas ligados à cultura tecnológica e pensamento computacional. Como resultado, constatou-se maior concentração ao realizarem as atividades; compreensão dos conceitos do pensamento computacional, da programação e da robótica; mudança em relação à percepção do erro; evolução da autonomia e o aprimoramento das soft skills.

\section{Introdução}

Segundo Kenski (2012), tecnologia é o conjunto de ferramentas e técnicas que cumprem seu papel, servindo à humanidade. Já o termo tecnologia educacional diz respeito aos recursos tecnológicos e ferramentas utilizadas para aprimorar o ensino-aprendizagem. Dessa forma, a tecnologia está a favor da educação. Há que se considerar que a educação também pode se utilizar de um conjunto de técnicas que usam conceitos da computação para solucionar problemas, desenvolvendo, assim, nos estudantes o pensamento computacional, que pode ser aplicado nas diversas áreas do conhecimento. Nesse sentido, a robótica pode ser uma estratégia para que se desenvolvam habilidades relacionadas ao pensamento computacional na educação básica.

O objetivo dessa pesquisa, que contou com o apoio do CNPq, foi desenvolver o pensamento computacional por meio da robótica, a fim de habituar a criança a generalizar soluções e assim poder aplicar nas mais diversas situações a serem vivenciadas durante a vida, unido ao conceito de decomposição que reduz o problema a 
VIII Congresso Brasileiro de Informática na Educação (CBIE 2019)

Anais do XXV Workshop de Informática na Escola (WIE 2019)

unidades mínimas, tornando mais fácil seu entendimento para, consequentemente, encontrar as possíveis soluções.

Bordini et al (2016) indicam, em seus estudos, que a robótica pedagógica é apresentada como um facilitador na aprendizagem de conceitos relacionados a Conceitos de Computação, Interdisciplinaridade e Colaboração e Comunicação.

Com um mundo informatizado e dinâmico, não faz sentido algum a inércia em que se encontram os métodos educacionais que ainda se aplicam na sociedade atual. Métodos esses, muita vezes, arcaicos e obsoletos que impedem a construção do conhecimento e geram a desmotivação e o desinteresse do estudante pelo aprendizado. [Teixeira e Kistemann Jr, 2017].

Considera-se, neste projeto, que o ensino na sociedade da informação deve produzir cooperativamente os conhecimentos, orientado para o máximo proveito das condições oferecidas, favorecendo o aprendizado personalizado e o aprendizado cooperativo, incentivando a interação, a colaboração, o respeito mútuo e o espírito de equipe, possibilitando a autonomia, a responsabilidade, a participação e o fortalecimento da identidade pessoal. Essa descentralização faz com que a prática educativa seja construída coletivamente. É nessa perspectiva que se pretende desenvolver as oficinas de robótica educacional propostas neste projeto.

\section{Metodologia}

A pesquisa-ação realizada permitiu observar, refletir sobre a realidade e entender o ponto de vista dos envolvidos. Utilizou-se como instrumentos de coleta de dados: observações in loco; fichas de acompanhamento e questionários. A iniciativa foi desenvolvida por meio de cursos de introdução à robótica, orientado pelo conceito de ensino híbrido, seguindo o modelo de rotação por estações. Foram trabalhados temas como cultura tecnológica; pensamento computacional; programação; lógica; construção e controle de dispositivos robóticos.

As oficinas ministradas nessa etapa foram baseadas nos métodos sócio individualizados: Método da descoberta - propõe uma situação de experiência e observação, o conhecimento é construído por meio do raciocínio indutivo; Método de solução de problemas - propõe uma situação problema e usa o conhecimento prévio do estudante para que ele elabore uma possível solução para a situação apresentada, enfatiza o raciocínio e a reflexão; Método de projetos - une o interesse e o esforço por meio de miniprojetos, para que ele possa desenvolver o raciocínio aplicado à vida real.

Tanto a avaliação dos estudantes quanto a avaliação das oficinas visavam verificar: i) a aprendizagem dos conceitos de computação; ii) a capacidade de resolução de problemas; iii) a capacidade de trabalho em equipe; iv) a capacidade de comunicação. Em relação aos questionários, foi realizada mineração de dados. Já no que se refere às fichas de acompanhamento foi utilizado o método de análise de conteúdo para análise dos dados.

\section{Resultados e Discussões}


VIII Congresso Brasileiro de Informática na Educação (CBIE 2019)

Anais do XXV Workshop de Informática na Escola (WIE 2019)

Foi observado nas oficinas do curso que alguns alunos já haviam tido contato com a robótica, seja pela programação em blocos ou pela construção de dispositivos. Nas atividades em grupo a maioria dos grupos optou por deixar um aluno como piloto e os demais como copilotos. Vale destacar que um dos alunos que é autista, ao construir os dispositivos robóticos, manteve sua concentração e atenção voltada para a atividade, realizando-a com autonomia, embora tivesse certa dificuldade motriz.

As atividades foram realizadas em grupos com a supervisão de um monitor que ia explicando passo a passo, assim os grupos conseguiram realizá-la. Os grupos que terminaram rápido a construção dos dispositivos puderam avançar em outros conceitos e o ensino personalizado pode ser posto em prática mais uma vez, dessa vez com grupos de até quatro componentes, observando um maior envolvimento dos estudantes.

Foi percebido nessas oficinas que uma das alunas que aparenta ter dificuldade de aprendizagem, mapeada pela escola, ao realizar os experimentos, os fez com atenção e cuidado, embora apresentasse certa dificuldade motora. Alguns alunos tiveram dificuldades em programar os circuitos. Um dos alunos que se encontrava em distorção idade-série demonstrou bastante interesse em realizar os experimentos, terminando com rapidez e com execução excelente, este mesmo aluno relatou que jamais havia "mexido com essas coisas de computador", nas palavras dele, e que a partir de agora iria estudar mais para poder trabalhar com a robótica.

Observou-se que os participantes conseguiram interiorizar os conceitos do pensamento computacional e da programação exemplificado tanto em seus relatos quanto no desempenho das atividades. Quanto à capacidade de resolução de problemas, vários participantes, embora cometessem erros, sentiam-se mais provocados a tentar novamente e novamente até que fizessem o dispositivo funcionar, o que demonstra que a percepção do erro é vista de forma diferente quando se tenta construir algo, servindo inclusive como fator motivador.

A aplicação de conceitos desenvolvidos em Ciências Naturais e em Matemática aconteceu de forma integrada às explicações sobre os conceitos envolvidos na robótica à medida que as atividades eram realizadas, isso fez com que as crianças percebessem que os conceitos dessas disciplinas estavam presentes na vida real, despertando ainda mais o interesse deles pelas atividades de robótica e principalmente pelo aprendizado.

Visto que as atividades propostas foram executadas em grupo, duas habilidades eram requeridas dos estudantes: a capacidade de trabalho em equipe e a capacidade de comunicação entre os membros da equipe. Como estratégia, eles foram agrupados segundo afinidades e mantiveram os mesmos grupos em toda(s) a(s) oficina(s). Embora no início tenham tido certa dificuldade em se organizar, a cada atividade que realizavam estavam mais conectados, o que tornava o trabalho mais fluido e aumentava a agilidade para cumprirem o que lhes era proposto.

Um ponto muito importante visto nessa fase e que merece destaque é que as crianças se preocupavam em ajudar umas as outras a realizarem as atividades, auxiliando e explicando como fazê-las. Quando alguém errava ou fazia de forma não correta, eles paravam e chamavam um dos regentes para pedir orientação. A autonomia se desenvolveu de forma tímida e estava atrelada à melhora da confiança delas ao realizarem as atividades. 
VIII Congresso Brasileiro de Informática na Educação (CBIE 2019)

Anais do XXV Workshop de Informática na Escola (WIE 2019)

Abaixo o Gráfico 1 - Média do desempenho nas atividades ilustra a média dos estudantes nas atividades desenvolvidas. $\mathrm{O}$ grupo foi separado entre meninas e meninos para que se pudesse comparar a desenvoltura deles e consequentemente desmistificar o senso comum de que robótica é para meninos. Colabora para isso os depoimentos de algumas estudantes como por exemplo "Tia, estou pensando em trabalhar com informática e robótica" estudante D; "Obrigada, eu consigo, eu fiz" estudante E. Esses depoimentos mostram como o contato com a tecnologia, logo no ensino fundamental, pode empoderar e trazer novas perspectivas de futuro para os jovens, principalmente para as garotas.

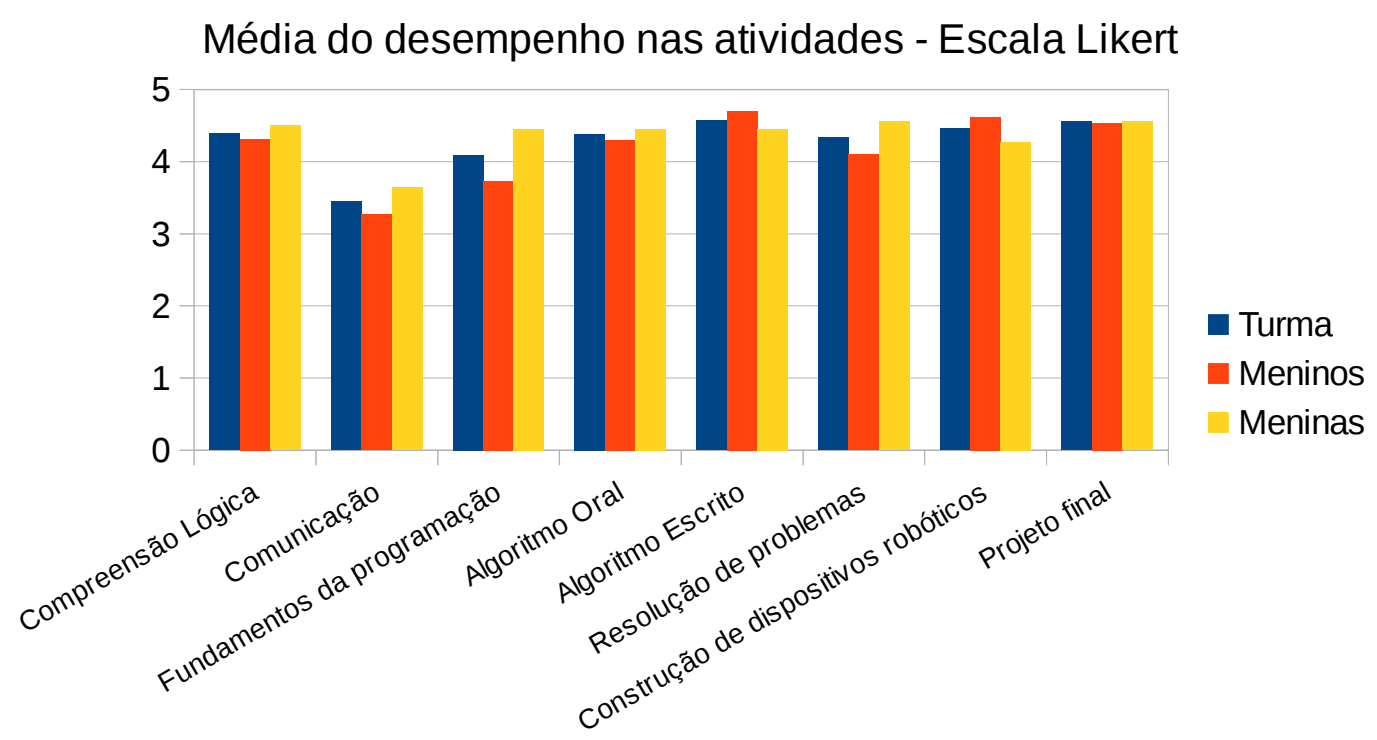

Gráfico 1 - Média do desempenho nas atividades

\section{Conclusão}

Atualmente utilizar a tecnologia no meio educacional se torna fundamental, uma vez em que se vive a era da informação. Na busca de métodos e instrumentos que motivem o estudante e o levem a construir seu próprio conhecimento, a robótica como ferramenta pedagógica se mostra eficaz, tornando a aprendizagem enriquecedora e significativa, pois leva em consideração que o conhecimento é construído a partir das experiências, ou seja, das interações com o meio, as pessoas e os objetos, estabelecendo vínculos entre a teoria e a prática.

Como desfecho desse projeto é apontado que os conceitos de computação propostos foram construídos com sucesso; que os envolvidos conseguiram compreender a capacidade de resolução de problemas não somente para solucionar as atividades, mas também para as tarefas cotidianas e que a capacidade de trabalho em equipe e a capacidade de comunicação são desenvolvidas de forma intrínseca e gradativa durante a realização das ações desenvolvidas. 
VIII Congresso Brasileiro de Informática na Educação (CBIE 2019)

Anais do XXV Workshop de Informática na Escola (WIE 2019)

Desse modo é preciso respeitar os talentos e os modos de aprendizagem diferentes, pois os alunos são dotados de inteligências múltiplas, sendo assim, devem ser estimulados a colocarem suas habilidades e competências a serviço da produção de conhecimento individual e coletivo, uma vez que a inovação não está restrita ao uso da tecnologia, mas como o professor lança mão de seus recursos.

O ensino do futuro, para ser eficaz, deve ter como princípio a cooperação, a interatividade, o diálogo, o respeito às diferenças, para incentivar o educando a aprender fazendo, considerando todas as informações e conteúdos disponíveis no mundo real, garantindo a ele o direito de escolha de seu objeto de estudo, de acordo com seus interesses e necessidades. Deve favorecer o aprendizado personalizado e o aprendizado cooperativo, incentivando a interação, a colaboração, o respeito mútuo e o espírito de equipe, possibilitando a autonomia, a responsabilidade, a participação e o fortalecimento da identidade pessoal.

Conclui-se que utilizar a robótica como objeto de ensino para uma interação interdisciplinar na educação é plausível e traz grandes benefícios aos discentes, proporcionando o desenvolvimento dos conceitos e tornando a aprendizagem enriquecedora e significativa, pois motiva a criança e a leva a construir seu próprio conhecimento a partir das experiências vividas, ou seja, das interações com o meio, as pessoas e os objetos, estabelecendo vínculos entre a teoria e a prática e possibilitando que elas atuem como construtoras de seus saberes.

\section{Referências Bibliográficas}

KENSKI Vani Moreira.(2012) Tecnologias e Ensino Presencial e a Distância. 3.ed. São Paulo: Papirus.

BORDINI, et al. (2016) Computação na educação básica no Brasil: estado da arte. Rev. Inform. Teor. Apl. (Online), Porto Alegre, v. 23, n. 2, p. 210-238, novembro

MIRANDA, Juliano Rodrigues; SUANNO, Marilza Vanessa Rosa. (2009) Robótica Pedagógica: prática pedagógica inovadora. In: IX Congresso Nacional de Educação EDUCERE e III Encontro Sul Brsileiro de Psicopedagogia. PUC Paraná, p. 8073-8086.

TEIXEIRA, Wesley Carminati; KISTERMANN Jr. Marco Aurélio. (2017) Uma investigação sobre a inserção da Educação Financeira em um Curso de Serviço de Matemática Financeira para graduandos de um curso de Administração. Educação Matemática Pesquisa: Revista do Programa de Estudos Pós-Graduados em Educação Matemática. São Paulo. v.19, n.1, 223-249. 